\title{
Production and flow of energy in chemosynthetic ecosystem at Onnuni Vent Field, Indian Ocean mid-ocean ridge
}

\author{
SUH YEON JEE ${ }^{1}$, SE-JONG JU ${ }^{1}$, MIN-SEOB KIM ${ }^{3}$
}

${ }^{1}$ Global Ocean Research Center, Korea Institute of Ocean Science and Technology, Korea; yjsuh@kiost.ac.kr; sjju@kiost.ac.kr

${ }^{2}$ Marine Environment Research Division, National Institute of Fisheries Science, Korea

We traced source and flow of energy in benthic fauna collected from the Onnuri Vent Field (OVF), a diffusive hydrothermal vent at Indian Ocean mid-ocean ridge. To do this, we analyzed sulfur $\left(\delta^{34} \mathrm{~S}\right)$, carbon $\left(\delta^{13} \mathrm{C}\right)$, and nitrogen $\left(\delta^{15} \mathrm{~N}\right)$ stable isotopic compositions in the vent fauna including mollusks, arthropods, and polychaetes and their potential food sources. The $\delta^{34} \mathrm{~S}$ values (range $=1.8 \%$ to $12.8 \%$ ) suggest that the OVF ecosystem is mainly sustained by chemosynthetic source of organic matter. Using $\delta^{13} \mathrm{C}$ values, we estimated the carbon fixation pathways of the chemosynthetic energy sources that may have been taken up by the higher trophic fauna. We found that the mussels ($31.7 \%$ ) may have derived their energy largely from the CBB cycle organic matter indicated by ${ }^{13} \mathrm{C}$-depleted $\delta^{13} \mathrm{C}$ values, whereas shrimp $(-15.0 \%)$, crab $(-16.5 \%)$, and gastropods ($11.5 \%$ ) may have taken organic matter produced by rTCA cycle or methanotrophs which have relatively high $\delta^{13} \mathrm{C}$ values. We will perform genetic analyses or compoundspecific stable isotope analyses to refine the interpretation of this study results. The shrimps have highest $\delta^{15} \mathrm{~N}$ values $(5.7 \%$ ) while gastropods and mussels have $10-15 \%$ lower $\delta^{15} \mathrm{~N}$ values $(-5.6 \%$ and $-13.5 \%$, respectively) than the shrimps. Such a large range in $\delta^{15} \mathrm{~N}$ values in these vent fauna reflect the occurrence denitrification and/or recycling of nitrogen causing the large nitrogen isotope fractionation. Based on the isotopes and prior study results, we identified the trophic guilds of the hydrothermal vent fauna from the OVF. We further compared the results to those from two other sites within the OVF in terms of their food web structure and trophic guilds. 